\title{
The Policy Effect of the National Modern Agricultural Demonstration Zones on the Growth of Local Agricultural Economy -Empirical Analysis Based on County Data in Sichuan Province
}

\author{
Yanyu Gong ${ }^{1}$ \\ ${ }^{1}$ College of Management, Sichuan Agricultural University, Chengdu, Sichuan, China
}

\begin{abstract}
Based on panel data of 178 counties (cities and districts) in Sichuan province from 2010 to 2018, this paper empirically tested the policy effect of establishing national modern agricultural demonstration zones on local agricultural economic growth by using the DID method. Research has shown that the establishment of the demonstration zones has a positive policy effect on agricultural economic growth, and the robustness test has proved the correctness of the model construction and the validity of the empirical results. However, further research found that the policy lacks a sustained promotion effect. The policy effect appeared a turning point in 2014 and then presents a stable trend. Therefore, this paper makes recommendations for the continuous development of agricultural modernization work in the future and the formulation of follow-up related policies.
\end{abstract}

\section{Introduction}

The development of Chinese agriculture and rural areas has entered a new historical stage, fundamental changes have taken place in the main contradiction of agriculture. In the report of the 19th National Congress of the Communist Party of China (CPC), General Secretary Xi Jinping proposed for the first time that agriculture and rural development should be given priority, and stressed during his inspection in Sichuan that the development of modern agriculture should be the focus of the implementation of the rural revitalization strategy [1]. Therefore, it is the strategic goal of strengthening and improving modern agriculture to deepen the structural reform of the agricultural supply-side, accelerate the cultivation of new drivers of agricultural and rural development, and create a new situation of agricultural modernization [2]. The Chinese government has planned the '13th Five-Year' modern agricultural goal, and proposed to basically realize the agricultural modernization of the national modern agricultural demonstration zones by 2020 . On the whole, highlighting the ability to guarantee food security, the competitiveness of agriculture, the living standards of farmers, and the improvement of the supply capacity and quality of agricultural products, so as to realize a modern agricultural industrial system with the integration of the three industries.

Since 2009, China has begun to explore and establish national modern agricultural demonstration zones. It is planned that within five years, a number of counties (districts and cities) will be selected and established as national modern agricultural demonstration zones with prominent leading role, high level of modern agriculture development and obvious driving role of demonstration. By seeking breakthroughs in points, it will promote the development of regional modern agriculture. Han Changfu, Chinese Minister of Agriculture, emphasized in the training class of national modern agricultural demonstration zones construction that demonstration zones is a pioneering area for modern agricultural development. It should focus on advancing the structural reform of the agricultural supply-side and strive to play a vanguard role in the constructions of a moderately prosperous society in all respects and the development of modern agriculture. As of 2020, there are 283 national modern agricultural demonstration zones in China.

Sichuan Province is a large agricultural province and shoulders the arduous task of China's agricultural modernization. In order to accelerate the leap from a big agricultural province to a strong agricultural province, it is necessary to take the implementation of the rural revitalization strategy as the overall focus of the 'agriculture, rural areas and farmers' (three rural) work in the new era, and take the development of modern agriculture as the top priority [1]. Sichuan Province has created 14 demonstration zones in five years, covering 34 counties (cities, districts).

Table1. Recognized list of national modern agricultural

\begin{tabular}{ccc} 
& \multicolumn{2}{c}{ demonstration zones } \\
\hline Batch & $\begin{array}{c}\text { Tim } \\
\mathrm{e}\end{array}$ & National modern agricultural demonstration zones \\
\hline First & 2010 & Chengdu, Guang'an District of Guang'an, Nanchong
\end{tabular}




\begin{tabular}{ccc} 
Second & 2012 & $\begin{array}{c}\text { Panzhihua, Dongpo District of Meishan, Jiangyang } \\
\text { District of Luzhou, Cangxi }\end{array}$ \\
Third & 2015 & $\begin{array}{c}\text { Jiangyou, Pengxi, Dazhu, Anyue, Hongyuan, Qianwei, } \\
\text { Luzhou }\end{array}$ \\
\hline
\end{tabular}

National modern agricultural demonstration zones is an important carrier and a powerful tool for China to accelerate agricultural modernization [3]. Its core competitiveness is based on the organizational management system, resources, and culture, and organically integrates science, technology, production methods, and operation mechanisms. In recent years, there have been endless researches on the construction of national modern agricultural demonstration zones. For example, Fengxian District, Shanghai emphasized ecological priority, Changde West Dongting Lake developed agricultural information application, Hubei Zaolin integrated fund, Sichuan Miyi developed rural tourism and other strategic ways to build the national modern agricultural demonstration zones. Some scholars have summarized five development models through field investigations in the demonstration zones. However, the development level of demonstration zones among provinces is unbalanced, and the problem of low development in the west and high development in the east is prominent. Most of the existing research perspectives are focused on the evaluation of the demonstration zone itself, but the research on the policy effect of the demonstration zones needs to be further studied. Thus, it is of great significance to study the influence of demonstration zones on the growth of county agricultural economy and evaluate the policy effect brought by demonstration zones from the perspective of regional economy for the implementation of modern agricultural construction related policies[3-12].

As an econometric method, the DID method is usually used to evaluate the effect of government policy implementation, and is widely used in policy analysis [1314]. Based on the panel data of counties (cities and districts) in Sichuan province from 2010 to 2018, this paper analyzed the policy effect of establishing demonstration zones on the agricultural economic growth of county in Sichuan province through the DID method, and put forward suggestions for exploring the implementation of policies to promote agricultural modernization in the future.

\section{Research hypothesis}

Jin Hao believed that supporting the industry development of the county, increasing the accumulation of capital and labor production factors of the county can promote its economic growth [15]. Gao Yunargued that increased investment in agricultural science and technology, innovation in systems and mechanisms, enhanced agricultural infrastructure construction, and improved farmers' quality, the benign drive of agricultural enterprises can improve the competitiveness of the demonstration zones, and it is proposed that the development of modern agriculture depends on the continuous growth of labor productivity, resource utilization rate and land output rate [10]. The creation of demonstration zones can provide favorable conditions for local area, such as preferential policy, increasing regional human capital, improving the investment environment, and optimizing government investment, thereby boosting agricultural economy of the county. This policy can activate the flow of factors, optimize the allocation of factors in a short time, improve the quality of production equipment and labor force, give prominent industries a higher development status, and then promote the development of regional agricultural economy.

Hypothesis 1: The establishment of national modern agricultural demonstration zones has a positive policy effect on the regional agricultural economy.

Wei Hong believed that policy of blood transfusion might squeeze out the local hematopoietic function, and restrict the local development capability, which would hinder local development [12]. Li Zheng suggested that the implementation of policies would lead to the agglomeration of regional elements, which would produce a certain siphonic effect on other surrounding cities and inhibit the positive effects brought by the policy [11]. Although policies can bring positive effects to the local agricultural economy in a short period of time, agricultural economic growth is affected by many aspects. If the research object is unable to cope with the interference of external factors, there will be the phenomenon of 'being pampered', gradually changing from 'policy support' to 'policy maintenance', and then the policy effect will gradually weaken. When other similar policies appear or the policy dividends are acting on competitors, then the policy may have a restraining effect. At this time, the growth of the agricultural economy is not actually the impact of the policy.

Hypothesis 2: The establishment of national modern agricultural demonstration zones will not maintain the positive policy effect for a long time, but may have a restraining effect.

\section{Model construction and variable description}

\subsection{Model construction}

In order to estimate the impact of the demonstration zones on the agricultural economic growth of county, the single difference method cannot be used to compare the difference in the level of agricultural economic development before and after the policy application, because this difference may not only be affected by the policy of demonstration zones, but also by other factors as well as other policies introduced in the same period, thus leading to estimation bias. A more effective method is to take advantage of the 'quasi-natural experiment' of setting up a demonstration zone and use the Difference-indifferences Method (DID) to eliminate the interference of these synchronic factors, so as to obtain the net effect of the demonstration zones on counties' economic growth. The basic logic of this method is that the counties where the demonstration zones is created are taken as the treatment group and the counties where no demonstration zones is created in the same period are taken as the control group. The change of economic growth level of the control 
group reflects the influence of other synchronic factors except the national modern agricultural demonstration zones, and the net effect of the demonstration zones on the agricultural economic growth of the county can be obtained when subtract the changes before and after the non-establishment counties from the difference in agricultural economic growth before and after the creation of the county.

Constructing an agricultural economic growth model based on the Cobb Douglas production function, this paper takes some counties (cities, districts) in Sichuan province as the research object. To construct the production function of county agricultural economic growth, it is necessary to pay attention that the production side not only includes labor factor and capital input factor, but also includes land factor, scientific and technological factor, and other factors that affect agricultural economic growth.

From this, the following panel DID benchmark model can be constructed:

$$
Y_{i t}=\beta_{0}+\beta_{1} \text { demo }_{i t}+\theta Z_{i t}+\mu_{i t}+\gamma_{t}+\varepsilon_{i t}
$$

Where, subscript i represents the county; $t$ represents the time; $Y_{i t}$ is the agricultural economic development level of the county $\mathrm{i}$ in the t period; $\mu_{i}$ is the individual fixed effect that does not change with time; $\gamma_{t}$ is the time fixed effect; $\varepsilon_{i t}$ is the random disturbance term; $Z_{i t}$ is a group of other control variables that may potentially affect the development level of the county's agricultural economy, including the logarithm of the number of labor force in agriculture, forestry, animal husbandry and fishery (lnal), the logarithm of the effective irrigation area (lniland), and the logarithm of the general budget expenditure of local finance (lnexp); demo is a policy dummy variable; demo it indicates whether a national modern agricultural demonstration zones has been created in the county $\mathrm{i}$ in year $\mathrm{t} ; \beta_{1}$ indicates the net effect of the demonstration zones on the agricultural economic development of the county, which is the core parameter of this paper. If $\beta_{l}$ is significantly positive, the implementation of the policy has indeed promoted the growth of the county's agricultural economy.

\subsection{Variable Description}

The sample time range of this paper is from 2010 to 2018 . Samples with severely missing data are excluded, and a small amount of important missing data are processed by linear interpolation method. There were 33 counties in the treatment group and 143 counties in the control group. The data are from Sichuan Statistical Yearbook, China County Statistical Yearbook (County and City Volume) and China County (City) Social and Economic Statistical Yearbook.

\subsubsection{Explained variable}

In this paper, the added value of agriculture, forestry, animal husbandry and fishery at the county level is used as the explained variable to measure the agricultural economic development level of each county, and logarithm processing is performed in the model.

\subsubsection{Core explanatory variable}

The core explanatory variable is demo, which represents whether to create a demonstration zone or not. If county i creates a demonstration zone in year $\mathrm{t}$, demo is assigned a value of 1 in year $t$ and years thereafter, otherwise 0 . The value of the dummy variable $d e m o^{k}$ in the kth year of creating a demonstration zone is: when the county creates a demonstration zone in the kth year, the value is 1 , otherwise it is 0 . In this paper, because the Notice of the Ministry of Agriculture on the Identification of the First Batch of National Modern Agricultural Demonstration Zones was issued in August 2010, the first batch of identification was set in 2011 in consideration of the policy delay, while the data of 2010 and earlier belong to the control group.

\subsubsection{Control variable}

According to the economic growth model based on the Cobb Douglas production function, in addition to the impact of the application of policies in the demonstration zones, other indicators that may affect the agricultural economic development of the county should also be considered when measure the agricultural economic development level of the county. From the Solow economic growth model, we can see that the development of agricultural economy is related to labor force, capital investment, land factors and technological progress.

\begin{tabular}{|c|c|c|}
\hline Variable & Name & Definition \\
\hline $\begin{array}{l}\text { Explaine } \\
\quad \mathrm{d} \\
\text { variable }\end{array}$ & $\underset{p}{\operatorname{lnagd}}$ & $\begin{array}{l}\text { Logarithm of the added value of county } \\
\text { agriculture, forestry, animal husbandry and } \\
\text { fishery }(10,000 \text { yuan })\end{array}$ \\
\hline \multirow[t]{4}{*}{$\begin{array}{l}\text { Explanat } \\
\text { ory } \\
\text { variables }\end{array}$} & demo & $\begin{array}{l}\text { Dummy variable of national modern } \\
\text { agricultural demonstration zones: } 1 \text { for the } \\
\text { policy implemented, } 0 \text { for the policy not } \\
\text { implemented }\end{array}$ \\
\hline & lnal & $\begin{array}{l}\text { Logarithm of labor force of agriculture, } \\
\text { forestry, animal husbandry and fishery }\end{array}$ \\
\hline & $\underset{d}{\operatorname{lnilan}}$ & $\begin{array}{c}\text { Logarithm of the effective irrigation area } \\
\text { (hectares) }\end{array}$ \\
\hline & $\ln \exp$ & $\begin{array}{l}\text { Logarithm of general budget expenditure of } \\
\text { local finance }\end{array}$ \\
\hline \multirow[t]{3}{*}{$\begin{array}{c}\text { Control } \\
\text { variables }\end{array}$} & $\operatorname{lnmp}$ & $\begin{array}{l}\text { Logarithm of total power }(10,000 \\
\text { kilowatts) of agricultural machinery }\end{array}$ \\
\hline & $\operatorname{lncf}$ & $\begin{array}{c}\text { Logarithm of scalar amount of fertilizer } \\
\text { application (Ton) }\end{array}$ \\
\hline & $\operatorname{lnec}$ & $\begin{array}{l}\text { Logarithm of rural electricity consumption } \\
(10,000 \text { kilowatts })\end{array}$ \\
\hline
\end{tabular}

Table3. Descriptive statistics of Variables

\begin{tabular}{ccccc}
\hline Name & Mean & $\begin{array}{c}\text { Standard } \\
\text { deviation }\end{array}$ & Minimum & Maximum \\
\hline lnagdp & 11.8 & 1.055 & 8.56 & 13.68 \\
demo & 0.143 & 0.35 & 0 & 1 \\
lnal & 11.29 & 0.914 & 4.605 & 13.11 \\
lniland & 8.995 & 1.444 & 1.946 & 11.6 \\
lnexp & 12.19 & 0.617 & 9.563 & 14.35 \\
lnmp & 7.422 & 0.942 & 3.101 & 9.238 \\
lncf & 8.645 & 1.9 & 0 & 11.36 \\
lnec & 8.474 & 1.431 & 2.996 & 11.05
\end{tabular}




\section{Empirical analysis}

\subsection{Average effect}

According to the model and indicator data mentioned above, this paper adopts the fixed-effect panel DID model to conduct regression estimation of policy effect, and the estimated results are shown in Table 4. In Table 4, model (1) does not include control variables, while model (2) adds control variables. The main focus of this paper is the policy effect, that is, the indicator of creating demonstration zones (demo). It can be seen from the table that regardless of whether the control variables is added, the regression coefficient of demo is positive and significant at the $1 \%$ level. It shows that the application of policies has had a very important positive impact on the development of local agricultural economy. However, comparing the coefficients of model (1) and model (2), we can know that the average effect of this policy is weakened after adding control variables, and we believe that adding control variables will make the regression coefficient closer to the real situation. Table 4 also shows the impact of other control variables on the county's agricultural economy. Each control variable in model (2) is positive and significant at the $1 \%$ level, which shows that the model is constructed reasonable and the variables selected have strong explanatory power, which provides guarantee for the correctness of the following study on the dynamic effect of this policy.

\begin{tabular}{|c|c|c|}
\hline $\begin{array}{l}\text { Explanatory } \\
\text { variable }\end{array}$ & $\begin{array}{l}\text { Model (1) } \\
\text { lnagdp }\end{array}$ & $\begin{array}{l}\text { Model (2) } \\
\text { lnagdp }\end{array}$ \\
\hline demo & $\begin{array}{c}0.6567 * * * \\
-8.79\end{array}$ & $\begin{array}{c}0.0988 * * * \\
-3.94\end{array}$ \\
\hline lnal & & $\begin{array}{c}0.4399 * * * \\
-25.23\end{array}$ \\
\hline lniland & & $\begin{array}{c}0.1326^{* * * *} \\
-9.88\end{array}$ \\
\hline $\ln \exp$ & & $\begin{array}{c}0.2892 * * * \\
-13.28\end{array}$ \\
\hline $\operatorname{lnmp}$ & & $\begin{array}{c}0.1216^{* * *} \\
-6.44\end{array}$ \\
\hline $\operatorname{lncf}$ & & $\begin{array}{c}0.0822 * * * \\
-7.95\end{array}$ \\
\hline $\operatorname{lnec}$ & & $\begin{array}{c}0.0566 * * * \\
-4.66\end{array}$ \\
\hline Constant term & $\begin{array}{c}11.7036 * * * \\
-419.78\end{array}$ & $\begin{array}{c}0.5667 * * \\
-2.36\end{array}$ \\
\hline Sample size & 1,584 & 1,584 \\
\hline Number of year & 9 & 9 \\
\hline R-squared & 0.047 & 0.906 \\
\hline
\end{tabular}

Note: $* * *, * *, *$ are significant at the levels of $1 \%, 5 \%$, and $10 \%$ respectively; the numbers in parentheses are t statistics.

\subsection{Dynamic effect}

This paper also needs to further study whether each identification demonstration zones has a promoting or inhibiting effect on the agricultural economic growth in the county? Does the second or third determination have sustained policy effects? The results are shown in Table 5 and Table 6 , and Table 6 is the case where no control variables are added. It can be seen that regardless of whether the control variables is added, the core explanatory variable demo is significantly positive at the level of $1 \%$ or $5 \%$. From the beginning of the policy implementation to 2018,8 years apart, the regression coefficient of demo form the overall downward trend, suggesting that the policy effect of the policy is gradually weakening over time. However, it cannot be explained that the identification of the second and third batch of demonstration zones has a restraining effect on them, because it shows a stable trend after 2015. As shown in Table 6, the policy effect reached a peak in 2011 and then began to decline, indicating that although the first batch of demonstration zones identified in 2011 produced good policy effect, the policy lacked sustained promotion. Although some demonstration zones were identified in 2011, but they did not play a positive role, and even suspected of inhibition. The inflection point of policy effect appeared in 2014, indicating that the identification of the third batch of demonstration zones has brought positive policy effect. It may be that the third batch has made up for the disadvantages caused by the second batch of demonstration zones, or it may be the policy effect of the second batch of demonstration zones has lagging behind.

Table5. Regression results 1 of policy dynamic effect

\begin{tabular}{|c|c|c|c|c|}
\hline & (1) & (2) & (3) & (4) \\
\hline Explanatory variable & Inagdp & Inagdp & Inagdp & Inagdp \\
\hline demo & $0.1875^{* *}$ & $0.1165^{* *}$ & $0.0930^{* *}$ & $0.0815^{* *}$ \\
\hline & $(2.31)$ & (2.15) & $(2.06)$ & $(2.08)$ \\
\hline Inal & $\begin{array}{c}0.4768^{* * *} \\
(13.11)\end{array}$ & $\begin{array}{c}0.4954^{* * *} \\
(1671)\end{array}$ & $\begin{array}{l}0.4618^{* * *} \\
(18.85)\end{array}$ & $\begin{array}{c}0.4639 * * * \\
(2073)\end{array}$ \\
\hline Iniland & $\begin{array}{c}0.1254^{* * * *} \\
\quad(3.69)\end{array}$ & $\begin{array}{c}0.0935^{* * *} \\
(3.90)\end{array}$ & $\begin{array}{c}0.1097^{* * *} \\
(5.29)\end{array}$ & $\begin{array}{c}0.1228 * * * \\
(6.50)\end{array}$ \\
\hline Inexp & $\begin{array}{l}0.2433^{* * *} \\
\quad(5.66)\end{array}$ & $\begin{array}{c}0.2807^{* * *} \\
(7.84)\end{array}$ & $\begin{array}{l}0.2887^{* * *} \\
(8.83)\end{array}$ & $\begin{array}{c}0.2650^{* * * *} \\
(9.28)\end{array}$ \\
\hline $\operatorname{lnmp}$ & $\begin{array}{c}0.1112^{* *} \\
(2.58)\end{array}$ & $\begin{array}{c}0.1195^{* * *} \\
\quad(3.50)\end{array}$ & $\begin{array}{c}0.1187^{* * *} \\
\quad(3.89)\end{array}$ & $\begin{array}{c}0.1217 * * * \\
(4.41)\end{array}$ \\
\hline Incf & $\begin{array}{c}0.0928^{* * *} * \\
(4.48)\end{array}$ & $\begin{array}{c}0.0807^{* * * *} \\
(4.71)\end{array}$ & $\begin{array}{c}0.0775^{* * *} \\
(5.10)\end{array}$ & $\begin{array}{c}0.0740^{* * * *} \\
(5.28)\end{array}$ \\
\hline Inec & $\begin{array}{c}0.0834^{* * *} \\
(3.13)\end{array}$ & $\begin{array}{c}0.0868^{* * *} \\
(4.06)\end{array}$ & $\begin{array}{c}0.0811^{* * *} \\
\quad(4.31)\end{array}$ & $\begin{array}{c}0.0757 * * * \\
(4.48)\end{array}$ \\
\hline Constant term & $\begin{array}{l}0.5164 \\
(1.07)\end{array}$ & $\begin{array}{l}0.1708 \\
(0.43)\end{array}$ & $\begin{array}{l}0.3757 \\
(1.02)\end{array}$ & $\begin{array}{c}0.5784^{*} \\
(1.73)\end{array}$ \\
\hline Sample size & 1,584 & 1,584 & 1,584 & 1,584 \\
\hline R-squared & 0.918 & 0.915 & 0.908 & 0.904 \\
\hline & (5) & (6) & (7) & (8) \\
\hline Explanatory variable & Inagdp & Inagdp & Inagdp & Inagdp \\
\hline demo & $\begin{array}{c}0.0961^{* * *} \\
(2.86)\end{array}$ & $\begin{array}{c}0.0969^{* * *} \\
(3.25)\end{array}$ & $\begin{array}{c}0.0947^{* * *} \\
(3.48)\end{array}$ & $\begin{array}{c}0.0988^{* * * *} \\
(3.94)\end{array}$ \\
\hline Inal & $\begin{array}{c}0.4616^{* * *} \\
(22.34)\end{array}$ & $\begin{array}{c}0.4557^{* * *} \\
(23.53)\end{array}$ & $\begin{array}{c}0.4445^{* * *} \\
(24.16)\end{array}$ & $\begin{array}{c}0.4399 * * * \\
(25.23)\end{array}$ \\
\hline Iniland & $\begin{array}{c}0.1239^{* * *} * \\
(7.58)\end{array}$ & $\begin{array}{c}0.1285^{* * *} \\
(8.47)\end{array}$ & $\begin{array}{c}0.1305^{* * * *} \\
(9.10)\end{array}$ & $\begin{array}{c}0.1326^{* * * *} \\
(9.88)\end{array}$ \\
\hline $\operatorname{lnexp}$ & $\begin{array}{c}0.2749 * * * \\
(10.36)\end{array}$ & $\begin{array}{c}0.2827 * * * \\
(11.40)\end{array}$ & $\begin{array}{c}0.3013^{* * *} \\
(12.83)\end{array}$ & $\begin{array}{c}0.2892 * * * \\
(13.28)\end{array}$ \\
\hline $\operatorname{lnmp}$ & $\begin{array}{l}0.1213^{* * *} \\
\quad(4.93)\end{array}$ & $\begin{array}{c}0.1189^{* * * *} \\
(5.35)\end{array}$ & $\begin{array}{c}0.1170^{* * * *} \\
(5.70)\end{array}$ & $\begin{array}{c}0.1216 * * * \\
(6.44)\end{array}$ \\
\hline Incf & $\begin{array}{c}0.0776^{* * *} \\
\quad(6.11)\end{array}$ & $\begin{array}{c}0.0791 * * * \\
(6.73)\end{array}$ & $\begin{array}{c}0.0821^{* * *} \\
(7.44)\end{array}$ & $\begin{array}{c}0.0822 * * * \\
(7.95)\end{array}$ \\
\hline Inec & $\begin{array}{c}0.0661 * * * \\
\quad(4.33)\end{array}$ & $\begin{array}{c}0.0603 * * * \\
(4.33)\end{array}$ & $\begin{array}{c}0.0549 * * * \\
\quad(4.24)\end{array}$ & $\begin{array}{c}0.0566 * * * * \\
(4.66)\end{array}$ \\
\hline Constant term & $\begin{array}{c}0.5205^{*} \\
(1.71)\end{array}$ & $\begin{array}{c}0.4966^{*} \\
(1.78)\end{array}$ & $\begin{array}{l}0.4098 \\
(1.57)\end{array}$ & $\begin{array}{c}0.5667 * * \\
(2.36)\end{array}$ \\
\hline Sample size & 1,584 & 1,584 & 1,584 & 1,584 \\
\hline R-squared & 0.905 & 0.906 & 0.905 & 0.906 \\
\hline
\end{tabular}

respectively; the numbers in parentheses are t statistics.

Table6. Regression results 2 of policy dynamic effect

\begin{tabular}{cccccc}
\hline $\begin{array}{c}\text { Explanatory } \\
\text { variable }\end{array}$ & demo & \multicolumn{3}{c}{$\begin{array}{c}\text { Constant } \\
\text { term }\end{array}$} & $\begin{array}{c}\text { Sample } \\
\text { size }\end{array}$ \\
\hline$(1)$ & $0.7775 * * *$ & $(2.93)$ & $11.6772 * * *$ & $(195.00)$ & 1,584 \\
$(2)$ & $0.7031 * * *$ & $(4.05)$ & $11.6413 * * *$ & $(237.81)$ & 1,584 \\
$(3)$ & $0.6798^{* * *}$ & $(4.95)$ & $11.6391 * * *$ & $(275.41)$ & 1,584 \\
$(4)$ & $0.6642 * * *$ & $(5.68)$ & $11.6458 * * *$ & $(309.16)$ & 1,584 \\
$(5)$ & $0.6631 * * *$ & $(6.59)$ & $11.6540 * * *$ & $(339.04)$ & 1,584 \\
$(6)$ & $0.6601 * * *$ & $(7.39)$ & $11.6688^{* * *}$ & $(367.43)$ & 1,584 \\
$(7)$ & $0.6583 * * *$ & $(8.12)$ & $11.6856 * * *$ & $(394.21)$ & 1,584 \\
$(8)$ & $0.6567 * * *$ & $(8.79)$ & $11.7036 * * *$ & $(419.78)$ & 1,584 \\
\hline
\end{tabular}


Note: $* * *, * *, *$ are significant at the levels of $1 \%, 5 \%$, and $10 \%$ respectively; the numbers in parentheses are t statistics.

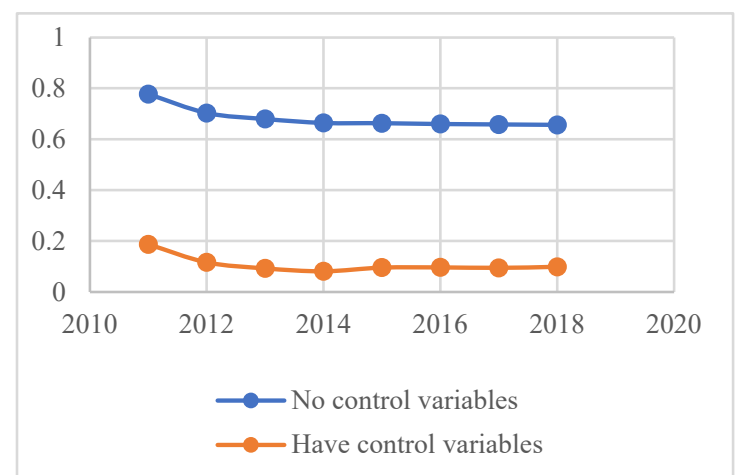

Fig 1. Trend chart of policy effect

\subsection{Robustness analysis}

\subsubsection{Randomness test}

Randomness is to test whether the sample is selected randomly, and it is necessary to confirm whether the sample is selected with bias for a specific index. Only by ensuring the randomness of policy choices, can policy effect be better measured. In order to judge whether the policy selection is random or not, the logit model is used with 'whether to create demonstration zones' as the explained variable (Wei Hong, Wang Kai, Chen Fan, 2019), and the indicator 'Ingdp' as an explanatory variable for quantitative analysis. The conclusion in Table 7 shows that the lngdp coefficient is not significant, and it is concluded that the policy selection complies with the principle of randomness.

Table7. Randomness test

\begin{tabular}{cc} 
Table $\%$ & demo \\
\hline Explanatory variable & 0.2969 \\
lnagdp & $(1.06)$ \\
Constant term & $-21.0565^{* * *}$ \\
& $(-8.37)$ \\
Sample size & 1,584
\end{tabular}

Note: $* * *, * *, *$ are significant at the levels of $1 \%, 5 \%$, and $10 \%$ respectively; the numbers in parentheses are $t$ statistics.

\subsubsection{Common trend test}

The important premise of using the DID model is that the treatment group and the control group need to follow the principle of common trend. This paper selected the data from 2006 to 2010 before the establishment of the demonstration zones, and calculated the average gross output value of agriculture, forestry, animal husbandry and fishery between the treatment group and the control group. As shown in Fig.2, the average agricultural economic development trend of the treatment group and the control group before the establishment of the demonstration zones was basically the same, which can prove that the treatment group and the control group are subject to the premise hypothesis of the quasi-natural experiment.

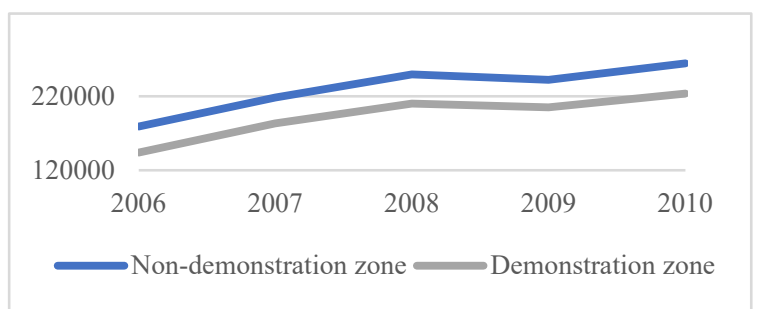

Fig 2. Common trend test

\subsubsection{Placebo test}

Even if the treatment group and the control group have the same trend before the policy is implemented, there is still concern about whether other policies affecting the trend change occurred, that is, the change in the trend of the treatment group and the control group after the policy intervention point may not really be caused by this policy, but by other polices at the same time. The following tests were carried out: the year before the implementation of the policy was selected for the fictitious processing group, and this paper positioned the research interval from 2006 to 2007 , assuming that the year of the implementation of the policy was 2007 , and then carried out regression to obtain the results as shown in the Table 8 . The results show that the dummy variable of whether to create demonstration zones (demo) is not significant, indicating that the fictitious research object has no policy effect, so agricultural economy of the county from 2010 to 2018 is indeed affected by the policy.

\begin{tabular}{|c|c|}
\hline Explanatory variable & lnagdp \\
\hline demo & $\begin{array}{l}0.0923 \\
(1.54)\end{array}$ \\
\hline lnal & $\begin{array}{c}0.4514 * * * \\
(11.96)\end{array}$ \\
\hline Iniland & $\begin{array}{c}0.0721 * * \\
(2.20)\end{array}$ \\
\hline $\ln \exp$ & $\begin{array}{c}0.3905 * * * \\
(7.96)\end{array}$ \\
\hline $\operatorname{lnmp}$ & $\begin{array}{c}0.1469 * * * \\
(3.47)\end{array}$ \\
\hline $\operatorname{lncf}$ & $\begin{array}{c}0.1191 * * * \\
(6.02)\end{array}$ \\
\hline $\operatorname{lnec}$ & $\begin{array}{c}0.0620 * * \\
(2.38)\end{array}$ \\
\hline Constant term & $\begin{array}{c}3.8503 * * * \\
(8.14)\end{array}$ \\
\hline
\end{tabular}

Note: $* * *, * *, *$ are significant at the evels of $1 \%, 5 \%$, and $10 \%$ respectively; the numbers in parentheses are $t$ statistics.

\section{Conclusions}

The empirical results show that in the 9 years since the establishment of the national modern agricultural demonstration zones, the county economic growth in Sichuan province has indeed been promoted by the policy. Although there were signs of weakening of the policy effect from 2011 to 2014, the establishment of a number of demonstration zones was approved by the Ministry of 
Agriculture in 2015, and the 'replace subsidies with awards' system was implemented in the same year, which allowed capital investment to be guided again, and modern agricultural development mechanisms were innovated, avoiding the risk of 'being pampered' in the demonstration zones. Thus, the policy effect from 2015 to 2018 showed a stable and efficient trend.

As assessed by the Ministry of Agriculture, so far, three counties (cities) in Sichuan province have entered the stage of basically realizing agricultural modernization, namely Chengdu, Nanchong, and Cangxi. The Chinese government pointed out in its guidance that by 2020 , more than half of the demonstration zones will enter the stage of basically realizing agricultural modernization. Although some demonstration zones have gradually formed large-scale and integrated agricultural production, and integrated the production and marketing of agricultural products, the follow-up tasks are still very difficult. Especially in the current context of the transformation and upgrading of the agricultural industry, the demonstration zones should play a demonstrative role from point to area. The introduction of policies also needs to be in line with the actual situation of agricultural development in each region. Local government should take the initiative to undertake the historical mission of realizing agricultural modernization, closely integrate the three phased goals of the rural revitalization strategy to strike a precise blow to the difficulties and blind spots that restrict the development of agricultural modernization.

Based on the requirements of the future agricultural modernization, the following suggestions are proposed for the implementation of modern agricultural construction policies:

Continue to deepen structural reforms in agricultural supply-side. The change of the supply structure requires a process, and the modern agricultural demonstration zones should play a demonstrative and leading role in the entire process from farmers' production to the formation of agricultural products, and promote the innovation and maturity of industrial modes. Under the condition of a market economy, the flow of factors is generally to highyield production sectors or regions, and the agricultural industry is relatively fragile and investment risks are also high. In order to give priority to the development of agriculture and rural areas, consideration should be given to the allocation of factors, capital investment and infrastructure construction in agricultural production sectors and regions, and the modern agricultural demonstration zones is a good entry point. At the same time, government should speed up the establishment of a support policy system and credit evaluation system for new business entities, and solve the bottlenecks encountered by new business entities in the reform in terms of investment and financing, tax reduction and exemption, and insurance services.

Optimize modern agricultural production mode. Modern agricultural production should shift from quantitative change to qualitative change, and the highquality agricultural production mode should reflect the greening of agriculture and the standardization of agriculture. Vigorously promote agricultural mechanization, promote high-quality, high-efficiency, and green production technologies, develop and produce environmentally safe new fertilizers and low-toxic, lowresidue pesticides, increase the utilization rate of pesticides and fertilizers for major crops, reduce resource waste, and strengthen assessment and evaluation of soil pollution prevention and control, strengthen soil pollution control and restoration. Modern agricultural demonstration zones should follow China's national food security guidelines, promote the construction of highstandard farmland on a large scale, ensure the red line of basic farmland protection, build high-standard farmland, and enhance the country's food security capabilities.

Moderately scaled operations to strengthen the modern agricultural organization system. Adhere to the basic status of family management in agriculture, realize the scale effect of pre-production, mid-production and postproduction socialized services, and reduce the cost of operating entities to obtain socialized services. By increasing material and technological inputs, reducing the proportion of labor inputs, producing high value-added agricultural products, increasing total factor productivity, and increasing the income of producers and operators. The social-enterprise mixed model of collective economy and private economy should be promoted, which not only developed the collective economy, but also mobilized the enthusiasm of social capital to participate in rural construction, incorporated various new types of business entities into the modern agricultural organization system, and gave full play to the role of agricultural organizations in modern agriculture. The leading role in modern agricultural development enables agricultural producers to reduce market risks, reduce production and transaction costs, and ensure the quality, safety and effective supply of agricultural products.

\section{Acknowledgment}

This work was supported by Key projects of National Social Science Fund"Study on the countermeasures to improve the quality of agricultural supply system under the sharing economy" (18BJY130)

\section{References}

1. Wang Dongming. (2018) Keep in mind that General Secretary Xi Jinping has placed great emphasis on promoting governance and development in Sichuan. Sichuan Daily, 001.

2. He Yaping, Jiang Heping. (2017) Development status of national modern agriculture demonstration zones and proposals for the development of the 13th FiveYear Plan. World Agriculture, 5.

3. Chen Jianping. (2017) Reform leads ecology to give priority to promoting fengxian modern agriculture demonstration zones construction. Shanghai Rural Economy, 2:31-33.

4. Wang Wubin, Zhou Yuancai, Tang Handong, et al. (2016) Zaoyang, Hubei: Integrating agriculturerelated funds to build a modern agriculture demonstration zone. Chinese finance, 8:50-51. 
5. Pan Xingyang. (2019) MiYi mode of modern agriculture with the characteristics of the whole industrial chain. Contemporary county economy, 9.

6. Du Yuneng, Pan Chiyu, Song Shufang. (2018) Evaluation of agricultural modernization in China by region -- Based on agricultural statistics of various provinces. Agrotechnical economy, 3.

7. Wang Jian, Xie Cong. (2016) Research on the construction of modern agricultural parks in Hebei province based on the coordinated development of Beijing, Tianjin and Hebei. China Soft Science, S2.

8. Jiang Heping, Wang Shuang. Main development models and countermeasures of national modern agriculture demonstration zones. Guangdong Agricultural Sciences. 2:169-175.

9. Sun Tian. Research on the development strategy of agricultural informatization in national modern agriculture demonstration zones -- Taking West Dongting of Changde City as an example. Huazhong Agricultural University.

10. Gao Yun, Jie Jian. (2012) Theoretical research on the core competitiveness of national modern agriculture demonstration zones. Anhui Agricultural Sciences, 33: 43-435.

11. Li Zheng, Yang Siying. (2019) Whether the national high-tech zone can improve the level of urban innovation? Southern economy, 1-16.

12. Wei Hong, Wang Kai, Chen Fan. (2019) Economic effect evaluation of the policy of carrying on industrial transfer demonstration zone. Statistics and Decision-making, 23: 123-127.

13. Zhou Yulong, Sun Jiuwen. (2019) Evaluation of the effectiveness of poverty alleviation and development policies aimed at poor counties -- an empirical study based on county data from 1990 to 2010. Nankai Economic Research, 1-20.

14. Zhang Hongyu. (2017) Strengthening and improving modern agriculture with chinese characteristics (People's Key Point). People's Daily. 05.

15. Jin Hao, Zhang Wenruo, LI Ruijing. (2020) Economic growth effect of poverty alleviation and development policy in key counties -- a quasi-natural experimental study based on county level data in Hebei Province. Economics and Management,01:27-34. 